\title{
Usage of, Preference for, and Satisfaction with Extended Eyelashes and False Eyelashes in Adult Women
}

Kyeong-Hwa Lee, Chae-Jeong Han*

Department of Beauty Art, Graduate School of Beauty Art, Youngsan University, Busan, Korea

\author{
*Corresponding author: Chae-Jeong Han, \\ Department of Beauty Art, Graduate School \\ of Beauty Art, Youngsan University, 142 \\ Bansongsunhwan-ro, Haeundae-gu, Busan \\ 48015, Korea \\ Tel.: +82516327098 \\ Fax: +82 515407193 \\ Email: beautyhan@ysu.ac.kr
}

Received February 22, 2017

Revised July 4, 2017

Accepted July 17, 2017

Published September 30, 2017

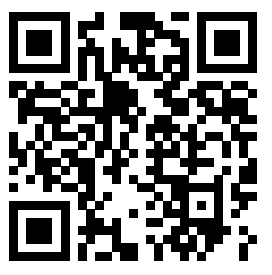

\begin{abstract}
Purpose: This study examined the usage of, preference for, and satisfaction with extended eyelashes and false eyelashes among Korean adult women. Methods: A self-administered questionnaire survey was conducted on adult women aged over 20 years; a total of 448 questionnaires were collected. The survey was conducted over 10 weeks, from April 30, 2016 to July 30, 2016. Results: Of all the subjects, $49.6 \%$ were in their 20 s, and $24.3 \%$ have an average monthly income of less than one million won. Further, $83.9 \%$ have extended eyelashes and $80.8 \%$ have used a special eyelash salon. Results showed that many were satisfied with their "clear eyes" (31.0\%). The reason to have eyelash cosmetics for the plurality was "to make my eyelashes long and abundant" (39.1\%). For subjects who received eyelash extension treatment, the preferred conditions were $0.15 \mathrm{~mm}$ thickness $(42.7 \%)$, black color (75.9\%), silk texture (29.4\%), JC curl (43.4\%), $11 \mathrm{~mm}$ length (42.7\%), and $80 \%$ density $(51.3 \%)$. Their extended eyelashes were rated by them at 4.16 (color), 4.11 (length), 3.72 (comfort), 3.58 (durability), 3.83 (cost-effectiveness), and 4.03 (general satisfaction). For subjects who received false eyelashes, the preferred conditions were black color (77.5\%), F curl (29.6\%), and $80 \%$ density (42.3\%). The scores for satisfaction for false eyelashes were 3.66 (color), 3.55 (length), 2.76 (comfort), 2.83 (durability), 3.39 (cost-effectiveness), and 3.27 (general satisfaction). The scores of satisfaction in color, length, comfort, durability, cost-effectiveness, and general satisfaction were significantly higher in extended eyelashes. Conclusion: These results can be used as preliminary data for the development of a cosmetics market in eyelashes.
\end{abstract}

Keywords: Preference, Satisfaction, Extended eyelashes, False eyelashes, Adult women

\section{Introduction}

현대사회는 아름다움에 대한 추구와 외모관리행동의 형태가 매 우 다양하게 변화되고 있다. 또한 매스컴의 영향이 확대되고 여성 들의 사회참여와 직업 전문화가 가속됨에 따라 자신의 이미지를 표 현할 기회가 많아졌다(Seol, 2008). 첫인상은 타인에게 자신의 이미 지를 각인시키는데 큰 역할을 하며, 사회적 상호 작용의 시작이면 서 추후 상호 작용의 결정요인이 된다. 이러한 첫인상은 얼굴에서 비롯되며 그 중에서도 눈이 차지하는 비중은 매우 커서 눈이 인상 을 좌우한다고 해도 과언이 아니다. 이러한 이유로 여러 연구들에 서 눈 화장을 피부나 헤어 등에 비해 더욱 중요하게 여기는 것을 알
수 있다(Shin, 2010).

속눈썹은 첩모 라고도 불리며 인체의 가장 중요하고 민감한 눈 의 일부를 구성하고 있다. 속눈썹은 눈꺼풀(eyelids) 가장자리를 따라 자라며, 위 속눈썹은 길이가 8-12 mm 이고 개수는 100-150 개 정도이며, 아래 속눈썹은 6-8 $\mathrm{mm}$ 에 50-75개 정도로 눈꺼풀 중앙 쪽이 가장 자리 쪽에 비해 약간 길이가 길다. 보통 속눈썹 은 4-6개월의 주기로 생성과 탈락을 반복한다(Kanski, 2007). 속 눈썹은 깜박이는 반사작용(blinking reflex)을 유발하여 누액(분 비액)을 아래, 위로 고르게 분산시키며, 강한 빛을 산란시켜 눈으 로 들어가는 빛의 양을 조절하고, 먼지, 벌레, 땀으로부터 눈을 보 호하는 역할을 한다(Shin, 2010). 또한, 속눈썹은 깊고 풍부해 보 
이는 눈을 연출하는데 큰 역할을 하며, 풍성하고 진한 속눈썹은 모든 여성에게서 매력, 자신감 및 건강함의 척도와 관련이 있다 (Draelos, 1991).

이렇듯 속눈썹을 가꾸는 속눈썹 미용은 자신의 눈매에 따라 맞 는 색상과 컬, 길이를 선택하여 매력적인 눈을 완성시켜주기 위한 도구이다. Grierson (2000)은 초기 속눈썹 미용은 신체 중 개방되 어 있고 취약한 부분, 특히 눈을 통해 나쁜 영혼이 들어온다고 믿 어 이를 막기 위해 여러 문화권에서 눈을 강하게 표현하기 시작한 것에서 유래되었다고 한다. 특히, 기원전 6,000년 전 고대 이집트 에서 코울(Kohl)이라는 검은 페이스트를 이용하여 눈 주변을 진하 게 발랐던 것을 속눈썹 미용 역사의 시초로 본다. 속눈썹 미용의 종 류로는 속눈썹을 올려주는 기구인 아이래쉬 컬러(Lim, 2007), 짙 고 풍성하고 긴 속눈썹 연출을 목적으로 하는 마스카라(Draelos, 2001; Volpe \& Ramirez, 2005), 실제 속눈썹처럼 만들어져 접착제 를 바르고 붙이는 일회용 속눈썹(Yang et al., 2013)과 인조 속눈썹 (false eyelashes)을 한 올 한 올 붙여 연장시키는 속눈썹 연장술(Seol, 2008) 등이 있다.

속눈썹 미용이 눈을 강조하는데 큰 역할을 함에도 불구하고 눈 화장과 관련해서는 대부분 눈썹(eyebrow)에 대한 연구가 주를 이 루고 있다. 눈썹화장 및 짙기 정도가 얼굴 이미지에 미치는 영향 (Gang, 2005; Kim \& Kang, 2014), 눈썹메이크업 디자인에 대한 분석 연구(Ha et al., 2005; Park, 2012) 등 다양한 연구들이 이루어 지고 있다. 반면, 속눈썹 미용은 다양한 연령층의 여성들에게 대중 화되고, 그에 따라 속눈썹 미용 분야의 시장이 활성화 되고 있지만 그에 대한 연구는 매우 부족한 실정이다.

이에 본 연구에서는 속눈썹 미용을 경험한 적이 있는 20 대 이상 성인여성을 대상으로 속눈썹 미용, 특히 속눈썹 연장과 일회용 속 눈썹에 대한 이용실태, 선호도 및 만족도를 파악하여 소비자를 만 족시키기 위한 속눈썹 미용의 발전방향을 모색하기 위한 기초자료 를 제공하고자 한다.

\section{Table 1. General characteristics of all subjects}

\begin{tabular}{|c|c|c|c|}
\hline Variables & Items & $\mathrm{N}$ & $\%$ \\
\hline \multirow{4}{*}{ Age } & $20 s$ & 222 & 49.6 \\
\hline & $30 \mathrm{~s}$ & 88 & 19.6 \\
\hline & $40 \mathrm{~s}$ & 84 & 18.8 \\
\hline & 50 s and older & 54 & 12.0 \\
\hline \multirow{4}{*}{ Residential district } & Seoul, Gyeonggi-do & 176 & 39.3 \\
\hline & Daejeon, Chungcheong-do & 20 & 4.5 \\
\hline & Busan, Gyeongsangnam-do & 250 & 55.8 \\
\hline & Others & 2 & 0.4 \\
\hline \multirow{2}{*}{ Marital status } & Single & 269 & 60.0 \\
\hline & Married & 179 & 40.0 \\
\hline \multirow{4}{*}{ Education level } & High school graduate and below & 125 & 27.9 \\
\hline & College & 209 & 46.7 \\
\hline & University & 96 & 21.4 \\
\hline & Graduate school & 18 & 4.0 \\
\hline \multirow{6}{*}{ Job } & Student & 161 & 35.9 \\
\hline & Company employee & 98 & 21.9 \\
\hline & Public official & 8 & 1.8 \\
\hline & Self-employed, service employee & 80 & 17.9 \\
\hline & Household & 71 & 15.8 \\
\hline & Others & 30 & 6.7 \\
\hline \multirow{6}{*}{ Average monthly income } & Under 1 million won & 109 & 24.3 \\
\hline & 1-2 million won & 85 & 19.0 \\
\hline & 2-3 million won & 71 & 15.8 \\
\hline & 3-4 million won & 23 & 5.1 \\
\hline & Over 4 million won & 15 & 3.3 \\
\hline & Others & 145 & 32.4 \\
\hline
\end{tabular}




\section{Methods}

\section{1. 연구대상 및 자료수집}

본 연구는 속눈썹 미용(속눈썹 연장, 일회용 속눈썹) 경험이 있 는 20세 이상 성인여성을 대상으로 2016년 4월 30일부터 7월 30 일까지 서울, 경기도, 대전, 충청도, 부산, 경상남도 지역을 중심 으로 실시되었다. 총 500 부의 설문지를 배포하여 회수된 464 부 중 응답이 불충분한 16 부를 제외한 설문지 총 448 부를 본 연구의 자료로 사용하였다.

\section{2. 측정항목 및 내용}

본 연구의 자료는 자기기입식 설문을 통해 수집되었다. 설문지 는 인구통계학적 특성 6 문항, 속눈썹 미용 이용실태 9 문항, 속눈 썹 미용 선호도 및 만족도 15 문항, 속눈썹 연장 선호도 6 문항, 일
회용 속눈썹 선호도 3 문항, 속눈썹 연장 및 일회용 속눈썹 만족도 각 6 문항으로 총 51 문항으로 구성되었다.

\section{3. 분석방법}

본 연구의 실증분석은 모두 유의수준 $5 \%$ 에서 검증하였으며, 통계처리는 Statistical Package for the Social Sciences (SPSS) 21.0 for windows 프로그램(IBM, USA)을 사용하여 분석하였다. 인구통계학적 특성, 속눈썹 연장 및 일회용 속눈썹 선호도는 빈도 분석을 통해 빈도와 백분율로 표시하였다. 또한, 속눈썹 연장과 일회용 속눈썹 만족도는 각 문항의 산술평균을 기술통계로 분석 하여 나타내었다. 속눈썹 연장과 일회용 속눈썹을 모두 받아본 경 험이 있는 대상자들을 대상으로, 만족도를 비교하기 위해 독립표 본 t-test (independent t-test)를 실시하였다.

Table 2. Usage of eyelashes cosmetic treatment

\begin{tabular}{|c|c|c|c|}
\hline Variables & Items & $\mathrm{N}$ & $\%$ \\
\hline \multirow{4}{*}{ Type of eyelashes cosmetic treatment } & Extended eyelashes & 376 & 83.9 \\
\hline & False eyelashes & 28 & 6.3 \\
\hline & Both of them & 43 & 9.6 \\
\hline & Others & 1 & 0.2 \\
\hline \multirow{2}{*}{ Change to one's image after eyelashes cosmetic treatment } & Yes & 444 & 99.1 \\
\hline & No & 4 & 0.9 \\
\hline \multirow{6}{*}{ Changed image after eyelashes cosmetic treatment } & Natural and comfortable image & 33 & 7.4 \\
\hline & Baby face image & 24 & 5.4 \\
\hline & Soft womanly image & 152 & 33.9 \\
\hline & Sophisticated image & 212 & 47.3 \\
\hline & Delicate image & 13 & 2.9 \\
\hline & Others & 14 & 3.1 \\
\hline \multirow{2}{*}{ Well-defined features after eyelashes cosmetic treatment } & Yes & 412 & 92.0 \\
\hline & No & 36 & 8.0 \\
\hline \multirow{2}{*}{ Good match for my skin tone } & Yes & 373 & 83.3 \\
\hline & No & 75 & 16.7 \\
\hline \multirow{2}{*}{ My face seems very small after eyelashes cosmetic treatment. } & Yes & 274 & 61.2 \\
\hline & No & 174 & 38.8 \\
\hline \multirow{2}{*}{$\begin{array}{l}\text { I'm most satisfied when I receive eyelashes cosmetic treatment } \\
\text { from specialist. }\end{array}$} & Yes & 404 & 90.2 \\
\hline & No & 44 & 9.8 \\
\hline \multirow{2}{*}{ Use of the special salon of eyelashes cosmetic treatment } & Yes & 362 & 80.8 \\
\hline & No & 86 & 19.2 \\
\hline \multirow{4}{*}{$\begin{array}{l}\text { Operator if you don't use the special salon of eyelashes } \\
\text { cosmetic treatment }\end{array}$} & Beautician & 13 & 15.1 \\
\hline & Nail artist & 38 & 44.2 \\
\hline & Aesthetician & 25 & 29.1 \\
\hline & Others & 10 & 11.6 \\
\hline
\end{tabular}


Table 3. Preference and satisfaction of eyelashes cosmetic treatment

\begin{tabular}{|c|c|c|c|}
\hline Variables & Items & $\mathrm{N}$ & $\%$ \\
\hline \multirow{4}{*}{ Desired image from eyelashes cosmetic treatment } & Pure image & 119 & 26.6 \\
\hline & Sharp image & 75 & 16.7 \\
\hline & Sexy image & 105 & 23.4 \\
\hline & Urban image & 149 & 33.3 \\
\hline \multirow{6}{*}{ The time of utilization of eyelashes cosmetic treatment } & Important appointment & 82 & 18.3 \\
\hline & Weekend & 31 & 6.9 \\
\hline & Regularly & 110 & 24.6 \\
\hline & Refresh oneself & 143 & 31.9 \\
\hline & Take over from make-up & 71 & 15.8 \\
\hline & Others & 11 & 2.5 \\
\hline \multirow{5}{*}{ Frequency of eyelashes cosmetic treatment (per a year) } & Under 10 times & 218 & 48.7 \\
\hline & 10-20 times & 156 & 34.8 \\
\hline & $21-31$ times & 53 & 11.8 \\
\hline & $32-42$ times & 7 & 1.6 \\
\hline & Others & 14 & 3.1 \\
\hline \multirow{4}{*}{ Reasonable average one-time cost of eyelashes cosmetic treatment } & $30,000-40,000$ won & 194 & 43.3 \\
\hline & $40,000-50,000$ won & 110 & 24.6 \\
\hline & $50,000-60,000$ won & 14 & 3.1 \\
\hline & Over 60,000 won & 2 & 0.4 \\
\hline \multirow{3}{*}{ Reasonable treat time of eyelashes cosmetic } & Under 30 min & 24 & 5.4 \\
\hline & $30 \mathrm{~min}-1 \mathrm{~h}$ & 380 & 84.8 \\
\hline & Over $1 \mathrm{~h}$ & 44 & 9.8 \\
\hline \multirow{6}{*}{ Annual average eyelashes cosmetic treatment cost } & Under 50,000 won & 61 & 13.6 \\
\hline & $50,000-100,000$ won & 43 & 9.6 \\
\hline & $100,000-200,000$ won & 128 & 28.6 \\
\hline & $200,000-300,000$ won & 109 & 24.3 \\
\hline & $300,000-400,000$ won & 81 & 18.1 \\
\hline & Over 400,000 won & 26 & 5.8 \\
\hline \multirow{3}{*}{ Satisfaction } & Very satisfied & 226 & 50.4 \\
\hline & Satisfied & 148 & 33.0 \\
\hline & Very unsatisfied & 3 & 0.7 \\
\hline \multirow{5}{*}{ Most satisfying part after eyelashes cosmetic treatment } & Eyes look very pretty. & 84 & 18.8 \\
\hline & Eyes look bigger. & 44 & 9.8 \\
\hline & Eyes look very clear. & 139 & 31.0 \\
\hline & Eyelashes look longer. & 53 & 11.8 \\
\hline & Eyelashes look heavy. & 128 & 28.6 \\
\hline \multirow{5}{*}{ Reason of eyelashes cosmetic treatment } & To make my eyes look bigger & 87 & 19.4 \\
\hline & To make my eyelashes long and abundant & 175 & 39.1 \\
\hline & To make my eyes look clearly & 163 & 36.4 \\
\hline & Unconsciously & 9 & 2.0 \\
\hline & Others & 14 & 3.1 \\
\hline \multirow{5}{*}{ Important part of eyelashes salon } & Interior & 5 & 1.1 \\
\hline & Service & 68 & 15.2 \\
\hline & Skill & 329 & 73.4 \\
\hline & Cost & 45 & 10.0 \\
\hline & Others & 1 & 0.2 \\
\hline \multirow{5}{*}{ Important part of facilities } & Interior space & 300 & 67.0 \\
\hline & Parking lot & 32 & 7.1 \\
\hline & Interior design & 72 & 16.1 \\
\hline & Rest area & 30 & 6.7 \\
\hline & Others & 14 & 3.1 \\
\hline \multirow{5}{*}{ Important part of service } & Rapidly respond to customer's demand & 254 & 56.7 \\
\hline & Attention to customers & 96 & 21.4 \\
\hline & Style of operator & 34 & 7.6 \\
\hline & Provision of the fashionable information & 55 & 12.3 \\
\hline & Others & 9 & 2.0 \\
\hline \multirow{4}{*}{ Important part of treatment skill } & Customer's demand & 110 & 24.6 \\
\hline & Fashionable style & 49 & 10.9 \\
\hline & Matched customer's style & 202 & 45.1 \\
\hline & Hour curtailment & 87 & 19.4 \\
\hline
\end{tabular}




\begin{tabular}{|c|c|c|c|}
\hline \multirow{5}{*}{ Important part of cost } & Low cost & 177 & 39.5 \\
\hline & Coupon & 33 & 7.4 \\
\hline & Event & 64 & 14.3 \\
\hline & Discount benefit & 168 & 37.5 \\
\hline & Others & 6 & 1.3 \\
\hline \multirow{4}{*}{ Location of salon } & Residential area & 206 & 46.0 \\
\hline & Main street & 169 & 37.7 \\
\hline & In shopping mall/department store & 43 & 9.6 \\
\hline & Others & 30 & 6.7 \\
\hline
\end{tabular}

\section{Results and Discussion}

\section{1. 인구통계학적 특성}

연구대상자의 인구통계학적 특성을 Table 1 에 나타내었다. 조 사대상자는 20대가 222명(49.6\%)으로 가장 많았고, 30대 88명 (19.6\%), 40대 84명(18.8\%), 50대 이상은 54명(12.0\%)으로 나타 났다. 거주지역은 부산, 경상남도 지역에 거주하는 사람이 250명 (55.8\%)으로 가장 많았고, 서울, 경기도 지역에 176명(39.3\%), 대전, 충청도 지역에 20 명 $(4.5 \%)$, 기타 지역에 2 명 $(0.4 \%)$ 거주하는 것으로 조사되었다. 결혼 여부에 대한 문항에서는 미혼자가 269명(60.0\%), 기혼자가 179 명 $40.0 \%$ )으로 조사되었다. 최종학력은 전문대 졸업자 가 209명(46.7\%)으로 가장 많았으며, 고등학교 졸업 이하는 125 명 (27.9\%), 대학교 졸업 96명(21.4\%), 대학원 졸업 이상은 18명(4.0\%) 으로 조사되었다. 직업 조사 결과, 학생이 161 명(35.9\%)으로 가장 많 은 비율을 차지하였고, 회사원 98명(21.9\%), 자영업 또는 서비스업 80명(17.9\%). 주부 71명(15.8\%), 기타 30명(6.7\%), 공무원 8명(1.8\%) 순으로 분포하였다. 대상자들의 월평균수입은 기타 응답자가 145 명 (32.4\%)으로 가장 많았고, 100만원 미만 109명(24.3\%), 100만원 이 상-200만원 미만 85명(19.0\%), 200만원 이상-300만원 미만 71명 (15.8\%), 300만원 이상-400만원 미만 23명(5.1\%), 400만원 이상 15 명(3.3\%)으로 조사되었다.

\section{2. 속눈썹 미용 이용실태}

Table 2는 속눈썹 미용 이용실태에 대한 결과이다. 받아본 속눈 썹 미용 시술 종류는 속눈썹 연장시술이 376명(83.9\%)으로 가장 많 았고, 속눈썹 연장과 일회용 속눈썹을 모두 사용해 본 경우가 43명 (9.6\%), 일회용 속눈썹 28 명(6.3\%), 기타 1 명 $(0.2 \%)$ 으로 조사되었 다. 속눈썹 미용 시술 후 이미지 변화 여부를 조사한 결과, 이미지 가 변화했다고 응답한 경우가 444명(99.1\%), 변화하지 않았다고 응 답한 경우가 4 명 $(0.9 \%)$ 으로 나타났다. 속눈썹 미용 시술 후 변화된 이미지를 조사한 결과, 시크하고 세련된 이미지가 212 명(47.3\%)으 로 가장 많았고, 부드럽고 여성스러운 이미지(152명; 33.9\%), 내추 럴하고 편안한 이미지(33명; $7.4 \%)$, 나이보다 어려 보이는 동안 이 미지(24명; $5.4 \%)$, 기타(14명; 3.1\%), 섬세하고 샤프한 이미지(13명; $2.9 \%)$ 순으로 나타났다. 속눈썹 미용 시술 후 이목구비가 뚜렷해졌 다고 생각하는가에 대한 질문에는 412 명(92.0\%)이 그렇다고 응답하 였고, 36 명(8.0\%)은 아니라고 응답하였다. 시술 받은 속눈썹 미용이
피부 톤과 잘 맞다고 생각하는가에 대한 질문에는 373명(83.3\%)이 그렇다고 응답하였고, 75 명(16.7\%)이 아니라고 응답하였다. 시술 후 얼굴이 작아 보인다고 생각하는가에 대한 질문에는 274명(61.2\%) 이 그렇다고 응답하였고, 174 명(38.8\%)이 아니라고 응답하였다. 속 눈썹 미용 시술을 전문가에게 받을 시 최고의 만족을 얻을 수 있다 고 생각하는가에 대한 질문에는 404명(90.2\%)이 그렇다고 응답하 였고, 44 명 $(9.8 \%)$ 이 아니라고 응답하였다. 속눈썹 미용 전문 살롱 의 이용 여부를 조사한 결과, 전문 살롱을 이용하는 경우는 362 명 (80.8\%)이었고, 전문 살롱을 이용하지 않는 경우는 86명(19.2\%)으 로 나타났다. 속눈썹 미용 전문 살롱을 이용하지 않는 86명은 네일 아트사(38명; 44.2\%), 피부관리사(25명; 29.1\%), 헤어미용사(13명; $15.1 \%)$, 기타(10명; $11.6 \%)$ 를 이용하는 것으로 조사되었다.

\section{3. 속눈썹 미용에 대한 전반적 선호도 및 만족도}

속눈썹 미용에 대한 전반적 선호도 및 만족도에 대한 결과를 살 펴보면(Table 3), 속눈썹 미용을 통해 얻고자 하는 이미지는 도시 적 이미지(149명; 33.3\%), 청순한 이미지(119명; $26.6 \%$ ), 섹시한 이 미지(105명; 23.4\%), 샤프한 이미지(75명; $16.7 \%)$ 순으로 조사되었 다. 속눈썹 미용 시술을 주로 이용하는 때를 묻는 문항에서는, 기 분전환 시 라고 응답한 대상자가 143명(31.9\%)으로 가장 많았고, 정기적으로 110 명(24.6\%), 중요한 약속 있을 때 82명(18.3\%), 메이 크업을 대체하기 위해 71명(15.8\%), 주말에 31명(6.9\%), 기타 11명 (2.5\%) 순으로 응답하였다. 속눈썹 미용 연 이용 횟수는 10 회 미만 (218명; 48.7\%)이 가장 많았고, 10-20회(156명; 34.8\%), 21-31회(53 명; 11.8\%), 기타(14명; 3.1\%), 32-42회(7명; 1.6\%) 순으로 조사되었 다. 속눈썹 미용 1 회 평균 지출 비용으로 적정한 수준에 대한 인식 을 조사한 결과, 3 만원 이상-4만원 미만이라고 응답한 사람이 194 명(43.3\%)이었고, 2 만원 이상-3만원 미만 128명(28.6\%), 4만원 이 상-5만원 미만 110 명(24.6\%), 5만원 이상-6만원 미만 14명(3.1\%), 6 만원 이상 2 명 $(0.4 \%)$ 으로 나타났다. 적정한 속눈썹 미용 시술 소요 시간 조사 결과, $30 \mathrm{~min}$ 이상-1 h 미만(380명; $84.8 \%$ )을 가장 선호 하는 것으로 조사되었고, $1 \mathrm{~h}$ 이상(44명; $9.8 \%), 30 \mathrm{~min}$ 미만(24명; $5.4 \%)$ 순으로 나타났다. 연 평균 속눈썹 미용 시술 지출 비용은 10 만원 이상-20만원 미만(128명; 28.6\%), 20만원 이상-30만원 미만 (109명; 24.3\%), 30만원 이상-40만원 미만(81명; 18.1\%), 5만원 미 만(61명; $13.6 \%), 5$ 만원 이상-10만원 미만(43명; 9.6\%), 40만원 이 상(26명; $5.8 \%$ ) 순으로 조사되었다. 시술 후 만족도를 조사한 결과, 
'매우 그렇다라고 응답한 대상자가 226명(50.4\%)으로 가장 많았고, '그렇다' (148명; 33.0\%), '보통이다' (54명; $12.1 \%$ ), '그렇지 않다' (17 명; 3.8\%), '매우 그렇지 않다' (3명; $0.7 \%$ ) 순으로 나타났다. 변화된 모습 중 가장 만족하는 부분을 조사한 결과, '눈이 선명해 보인다라 고 응답한 대상자가 139명(31.0\%)으로 가장 많았고, '속눈썹이 풍성 해 보인다'가 128 명(28.6\%), '눈이 예뼈 보인다' 84 명(18.8\%), '속눈썹 이 길게 보인다' 53 명(11.8\%), '눈이 커 보인다' 44명(9.8\%) 순으로 나 타났다. 속눈썹 미용 시술 이유로는, '속눈썹이 길고 숱이 많게 하기 위하여'라고 응답한 사람이 175 명(39.1\%)으로 가장 많았고, '눈매가 선명하게 보이게 하기 위하여'라고 응답한 사람 163 명(36.4\%), '눈 을 커 보이게 하기 위하여'에 응답한 사람이 87명(19.4\%), 기타 14 명 (3.1\%), 무의식적으로 9 명(2.0\%)으로 조사되었다.
속눈썹 미용 살롱 방문 시 우선적으로 생각하는 사항을 조사한 결 과, 미용사의 시술 기술이라고 응답한 대상자가 329명(73.4\%)으로 가장 많았고, 미용사의 서비스라고 응답한 경우가 68명(15.2\%), 시 술 가격이라고 응답한 경우가 45 명(10.0\%), 인테리어라고 응답한 경 우가 5명(1.1\%), 기타 응답이 1명(0.2\%) 순으로 나타났다. 속눈썹 미 용 살롱 시설 중 가중 중요한 사항을 조사한 결과, 내부공간(300명; $67.0 \%)$ 을 가장 우선적으로 고려하는 것으로 나타났고, 실내인테리 어(72명; 16.1\%), 주차장(32명; $7.1 \%)$, 휴식공간(30명; $6.7 \%)$, 기타 (14명; $3.1 \%$ ) 순으로 조사되었다. 속눈썹 미용사의 서비스 중 가장 우선적으로 생각하는 사항을 조사한 결과, '고객의 요구에 신속히 대응하는 것(254명; $56.7 \%)$ 을 가장 중요하게 생각하는 것으로 나타 났고, '고객들에게 관심'이 96명(21.4\%), '유행 정보 지식 제공'이 55

Table 4. Preference of extended eyelashes

\begin{tabular}{|c|c|c|c|}
\hline Variables & Items & $\mathrm{N}$ & $\%$ \\
\hline \multirow{4}{*}{ Thickness } & $0.10 \mathrm{~mm}$ & 93 & 22.2 \\
\hline & $0.15 \mathrm{~mm}$ & 179 & 42.7 \\
\hline & $0.18 \mathrm{~mm}$ & 85 & 20.3 \\
\hline & $0.20 \mathrm{~mm}$ & 62 & 14.8 \\
\hline \multirow{5}{*}{ Color } & Black & 318 & 75.9 \\
\hline & Purple & 1 & 0.2 \\
\hline & Dark brown & 95 & 22.7 \\
\hline & Red & 0 & 0.0 \\
\hline & Others & 5 & 1.2 \\
\hline \multirow{7}{*}{ Type of texture } & Nature & 82 & 19.6 \\
\hline & Volume & 75 & 17.9 \\
\hline & Silk & 123 & 29.4 \\
\hline & Mink & 16 & 3.8 \\
\hline & Velvet & 38 & 9.1 \\
\hline & Natural hair & 31 & 7.4 \\
\hline & I don't know well. & 54 & 12.9 \\
\hline \multirow{5}{*}{ Type of curl } & J & 118 & 28.2 \\
\hline & $\mathrm{JC}$ & 182 & 43.4 \\
\hline & $\mathrm{C}$ & 91 & 21.7 \\
\hline & $\mathrm{CC}$ & 21 & 5.0 \\
\hline & D & 7 & 1.7 \\
\hline \multirow{5}{*}{ Length } & $9 \mathrm{~mm}$ & 45 & 10.7 \\
\hline & $10 \mathrm{~mm}$ & 152 & 36.3 \\
\hline & $11 \mathrm{~mm}$ & 179 & 42.7 \\
\hline & $12 \mathrm{~mm}$ & 39 & 9.3 \\
\hline & Others & 4 & 1.0 \\
\hline \multirow{4}{*}{ Density } & $40 \%$ & 3 & 0.7 \\
\hline & $50 \%$ & 68 & 16.2 \\
\hline & $80 \%$ & 215 & 51.3 \\
\hline & $100 \%$ & 133 & 31.7 \\
\hline
\end{tabular}


명(12.3\%), '미용사의 스타일'이 34 명(7.6\%), 기타 9명(2.0\%) 순으 로 응답하였다. 속눈썹 미용사의 시술 부분에서 우선적으로 생각하 는 사항을 조사한 결과, 고객 유형에 맞게 하는 것(202명; $45.1 \%)$ 을 가장 중요하게 생각하는 것으로 나타났고, 고객의 요구사항에 맞는 시술(110명; 24.6\%), 기술에 따른 시간 단축(87명; 19.4\%), 유행 스 타일을 알아서 시술(49명; $10.9 \%)$ 순으로 조사되었다. 속눈썹 미용 살롱 이용 시 요금 부분에서 우선이라 생각하는 사항을 조사한 결 과, 저렴한 가격(177명; $39.5 \%)$ 이라고 응답한 사람이 가장 많았고, 할인혜택(168명; 37.5\%), 이벤트 제공(64명; 14.3\%), 쿠폰제(33명; $7.4 \%)$, 기타(6명; $1.3 \%)$ 순으로 응답한 것으로 나타났다. 주로 이용 하는 속눈썹 미용 살롱의 위치를 조사한 결과, 아파트단지 및 주택 가(206명; $46.0 \%)$ 의 미용 살롱을 이용하는 경우가 가장 많은 것으 로 나타났고, 중심지 번화가(169명; $37.7 \%)$, 쇼핑몰 및 백화점 내(43 명; 9.6\%), 기타(30명; 6.7\%) 순으로 조사되었다.

\section{4. 속눈썹 연장 선호도 및 만족도}

속눈썹 연장에 대한 선호도는 Table 4에 제시하였다. 속눈썹 연 장 시 선호하는 굵기를 조사한 결과, $0.15 \mathrm{~mm}$ (179명; $42.7 \%)$ 를 가 장 선호하는 것으로 나타났고, $0.10 \mathrm{~mm}$ (93명; $22.2 \%), 0.18 \mathrm{~mm}$ (85명; 20.3\%), $0.20 \mathrm{~mm}$ (62명; $14.8 \%$ ) 순으로 선호하는 것으로 조 사되었다. 속눈썹 연장 시 선호하는 컬러를 조사한 결과, 검정(318 명; $75.9 \%)$ 을 가장 선호하는 것으로 나타났고, 다크브라운(95명; $22.7 \%)$, 기타( $(5$ 명; $1.2 \%)$, 보라(1명; $0.2 \%)$, 빨강( 0 명; $0.0 \%$ ) 순의 선 호도를 보였다. 자주 시술 받는 속눈썹 모의 종류를 조사한 결과, 실 크 모(123명; 29.4\%)가 가장 많은 비율을 차지하였고, 내추럴 모(82

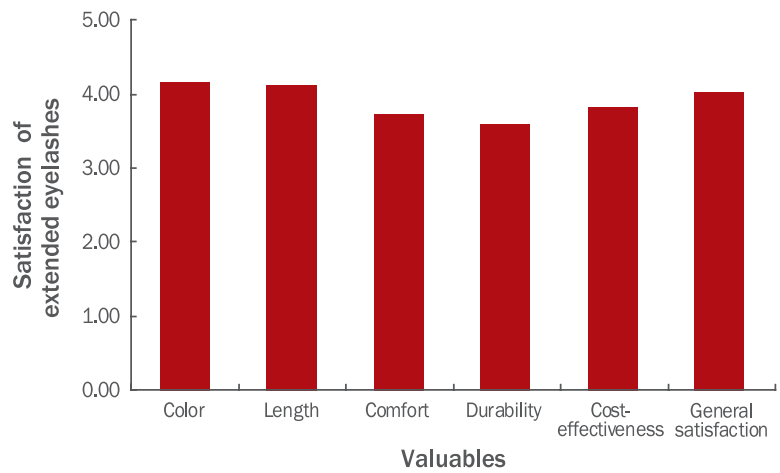

Figure 1. Satisfaction of extended eyelashes in experienced subjects.

The scores of extended eyelashes were 4.16 (color), 4.11 (length), 3.72 (comfort), 3.58 (durability), 3.83 (cost-effectiveness), and 4.03 (general satisfaction). Variables are expressed as means.

명; 19.6\%), 볼륨 모(75명; 17.9\%), 잘 모름(54명; $12.9 \%)$, 벨벳 모 (38명; 9.1\%), 천연 모(31명; 7.4\%), 밍크 모(16명; 3.8\%) 순으로 조 사되었다. 속눈썹 연장 시 선호하는 컬을 조사한 결과, JC컬(182명; 43.4\%)을 가장 선호하는 것으로 나타났고, J컬(118명; 28.2\%), C컬 (91명; 21.7\%), CC컬(21명; 5.0\%), D컬(7명; 1.7\%) 순의 선호도를 보 였다. 속눈썹 연장 시 선호하는 길이를 조사한 결과, $11 \mathrm{~mm}$ (179명; 42.7\%), 10 mm (152명; 36.3\%), 9 mm (45명; 10.7\%), 12 mm (39 명; 9.3\%), 기타(4명; $1.0 \%$ ) 순으로 조사되었다. 속눈썹 연장 시 선 호하는 밀도를 조사한 결과, 풍성하고 자연스러운 $80 \%$ 밀도(215명; $51.3 \%)$ 를 가장 선호하는 것으로 나타났고, 풍성하고 촘촘하게 진한

Table 5. Preference of false eyelashes

\begin{tabular}{|c|c|c|c|}
\hline Variables & Items & $\mathrm{N}$ & $\%$ \\
\hline \multirow{5}{*}{ Color } & Black & 55 & 77.5 \\
\hline & Purple & 0 & 0.0 \\
\hline & Dark brown & 16 & 22.5 \\
\hline & Red & 0 & 0.0 \\
\hline & Others & 0 & 0.0 \\
\hline \multirow{7}{*}{ Type of curl } & D & 19 & 26.8 \\
\hline & $D G$ & 19 & 26.8 \\
\hline & $F$ & 21 & 29.6 \\
\hline & F (special) & 2 & 2.8 \\
\hline & SF & 8 & 11.3 \\
\hline & SF (special) & 0 & 0.0 \\
\hline & Others & 2 & 2.8 \\
\hline \multirow{4}{*}{ Density } & $40 \%$ & 1 & 1.4 \\
\hline & $50 \%$ & 29 & 40.8 \\
\hline & $80 \%$ & 30 & 42.3 \\
\hline & $100 \%$ & 11 & 15.5 \\
\hline
\end{tabular}




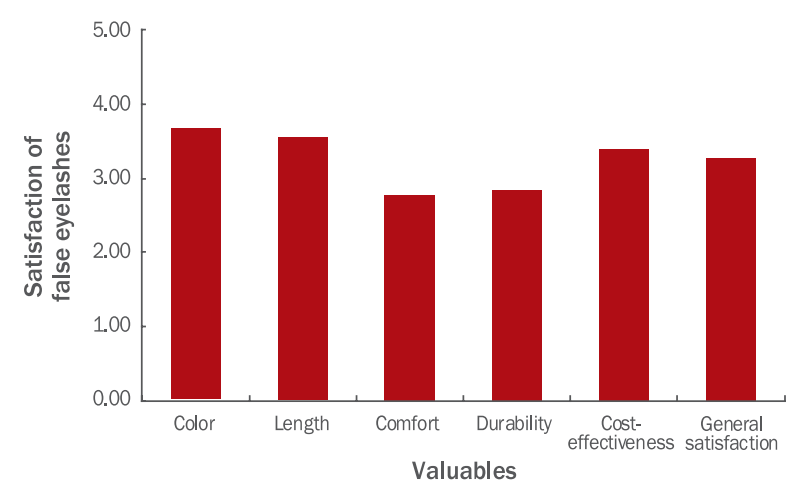

Figure 2. Satisfaction of false eyelashes in experienced subjects. The scores of false eyelashes were 3.66 (color), 3.55 (length), 2.76 (comfort), 2.83 (durability), 3.39 (cost-effectiveness), and 3.27 (general satisfaction). Variables are expressed as means.

$100 \%$ 밀도(133명; $31.7 \%)$, 자연스럽게 한 듯 안 한 듯 $50 \%$ 밀도(68 명; $16.2 \%)$, 조금 듬성듬성하게 안 한 듯 $40 \%$ 밀도(3명; $0.7 \%$ ) 순의 선호도를 보였다.

속눈썹 연장 이용자의 시술 만족도는 5점 만점으로 계산하여 Figure 1에 제시하였다. 컬러 만족도는 평균 4.16점, 길이 만족도는 평균 4.11점, 불편감 만족도는 평균 3.72점, 지속성 만족도는 평균 3.58 점, 가격대비효과 만족도는 평균 3.83점, 전반적인 만족도는 평 균 4.03점으로 조사되었다.

\section{5. 일회용 속눈썹 선호도 및 만족도}

Table 5는 일회용 속눈썹 선호도에 대한 결과이다. 선호하는 일 회용 속눈썹 컬러를 조사한 결과, 검정이라고 응답한 사람이 55 명 (77.5\%), 다크브라운이 16 명(22.5\%)으로 나타났고, 이외의 컬러를 사용한다고 응답한 경우는 없었다. 선호하는 일회용 속눈썹 컬은 $\mathrm{F}$ 컬이 21명(29.6\%)으로 가장 선호하는 컬로 나타났고, D컬과 DG컬 이 각각 19 명(26.8\%), $\mathrm{SF}$ 컬이 8명(11.3\%), F특컬과 기타라고 응답한 경우가 각각 2 명(2.8\%)으로 조사되었다. 선호하는 일회용 속눈썹 밀 도를 조사한 결과, 풍성하고 자연스러운 $80 \%$ 밀도(30명; $42.3 \%$ )를 가장 선호하는 것으로 나타났고, 내추럴하게 한 듯 안 한 듯 $50 \%$ 밀 도(29명; 40.8\%), 풍성하고 촘촘하게 진한 $100 \%$ 밀도(11명; $15.5 \%)$, 조금 듬성듬성하게 안 한 듯 $40 \%$ 밀도(1명; $1.4 \%$ ) 순의 선호도를 보 였다.

컬러 만족도는 평균 3.66 점, 길이 만족도는 평균 3.55 점, 불편감 만족도는 평균 2.76 점, 지속성 만족도는 평균 2.83점, 가격대비효과 만족도는 평균 3.39점, 전반적인 만족도는 평균 3.27점으로 조사되 었다(Figure 2).

\section{6. 속눈썹 연장과 일회용 속눈썹의 만족도 비교}

속눈썹 연장과 일회용 속눈썹을 모두 사용해 본 경험이 있는 43

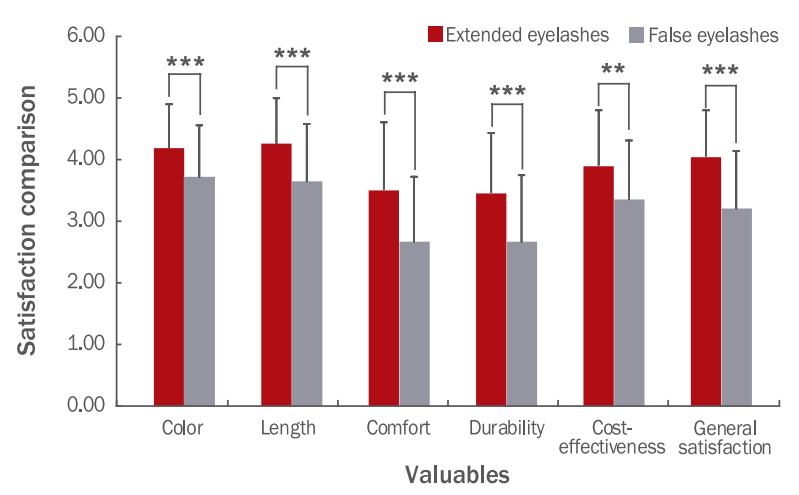

Figure 3. Comparison of satisfaction between extended and false eyelashes.

Comparisons of satisfaction between extended and false eyelashes in forty three subjects experienced extended and false eyelashes. The scores of satisfaction on color, length, comfort, durability, cost-effectiveness, and general satisfaction in extended eyelashes were significantly higher than in false eyelashes. The $p$-values for differences within group between extended and false eyelashes by paired t-test $\left({ }^{* *} p<0.05 ;{ }^{* * *} p<0.001\right)$.

명의 두 시술 만족도를 비교한 결과는 Figure 3에 제시하였다. 컬 러에 대한 만족도는 속눈썹 연장이 4.19점, 일회용 속눈썹이 3.72 점 $(p=0.0003)$, 길이에 대한 만족도는 속눈썹 연장이 4.26점, 일회 용 속눈썹이 3.63점 $(p=0.0004)$, 불편감에 대한 만족도는 속눈썹 연 장이 3.51점, 일회용 속눈썹은 2.65 점 $(p=0.0008)$, 지속성에 대한 만 족도는 각각 3.47 점, 2.65 점 $(p=0.0005)$, 가격대비효과에 대한 만 족도는 속눈썹 연장이 3.91점, 일회용 속눈썹이 3.35점 $(p=0.0080)$, 전반적 만족도는 속눈썹 연장이 4.05점, 일회용 속눈썹이 3.21점 ( $p<0.0001)$ 으로 6 가지 평가 영역 모두에서 속눈썹 연장 만족도가 일 회용 속눈썹 만족도에 비해 높게 나타났다.

\section{Conclusion}

본 연구는 속눈썹 미용 경험이 있는 20대 이상 성인여성을 대상 으로 속눈썹 연장과 일회용 속눈썹의 이용실태, 선호도 및 만족도를 파악하였으며, 결론은 다음과 같다.

첫째, 총 대상자 448명 중 49.6\%가 20대로 가장 많았으며, 미혼 이 $60.0 \%$ 였으며, $35.9 \%$ 가 학생이라고 응답하였다.

둘째, 속눈썹 미용 경험이 있는 대상자들의 83.9\%가 속눈썹 연장 을 경험해보았으며, 속눈썹 미용 시술 후 $99.1 \%$ 가 이미지가 변화했 다고 응답하였다. 총 대상자의 $90.2 \%$ 가 속눈썹 미용 전문가에게 시 술을 받을 때 최고의 만족을 얻을 수 있다고 생각하였으며, 속눈썹 미용 전문 살롱을 이용하는 경우는 $80.8 \%$ 였다. 속눈썹 미용 전문 살 롱을 이용하지 않는 대상자의 $44.2 \%$ 는 네일아트사에게 시술을 받 는 것으로 조사되었다. 
셋째, 속눈썹 미용을 통해 얻고자 하는 이미지로는 도시적 이미 지가 $33.3 \%$ 로 가장 높았으며, 기분 전환이 필요할 때 속눈썹 미용 을 받는다고 응답한 대상자는 $31.9 \%$ 였다. 연 10 회 미만으로 속눈썹 미용을 이용하는 대상자가 $48.7 \%$ 로 가장 많았고, $43.3 \%$ 가 적정 1 회 평균 지출 비용은 3 만원 이상-4만원 미만이라고 응답하였다. 적정 한 속눈썹 미용 시술 소요시간은 $30 \mathrm{~min}$ 이상- $1 \mathrm{~h}$ 미만(84.8\%)을 가 장 선호하였고, 연 평균 속눈썹 미용 시술 지출 총 비용은 10 만원 이 상-20만원 미만이 $28.6 \%$ 로 가장 많았다. 시술 후 만족도를 조사한 결과 '매우 그렇다'라고 응답한 대상자가 전체의 $50.4 \%$ 로 가장 높았 다. 시술 후 가장 만족하는 부분은 '눈이 선명해 보인다'로 $31.0 \%$ 를 차지하였으며, 속눈썹 미용 시술 이유로는 '속눈썹이 길고 숱이 많 게 하기 위하여라고 응답한 경우가 $39.1 \%$ 이었다.

넷째, 속눈썹 연장 선호도 및 만족도를 살펴 본 결과, 속눈썹 연 장 시 선호하는 굵기는 $0.15 \mathrm{~mm}$ (42.7\%), 검정색(75.9\%), 실크 모 (29.4\%), JC컬(43.4\%), 길이는 $11 \mathrm{~mm}$ (42.7\%), 풍성하고 자연스러 운 $80 \%$ 정도의 밀도(51.3\%)로 조사되었다. 속눈썹 연장 컬러 만족 도는 평균 4.16점, 길이 만족도는 평균 4.11점, 불편감 만족도는 평 균 3.72점, 지속성 만족도는 평균 3.58점, 가격대비효과 만족도는 평균 3.83점, 전반적인 만족도는 평균 4.03 점으로 조사되었다.

다섯째, 일회용 속눈썹의 선호도 및 만족도로, 가장 선호하는 컬 러는 검정색(77.5\%), 컬은 F컬(29.6\%), 밀도는 풍성하고 자연스러운 80\% (42.3\%)로 나타났다. 일회용 속눈썹 컬러 만족도는 평균 3.66 점, 길이 만족도는 평균 3.55 점, 불편감 만족도는 평균 2.76 점, 지속 성 만족도는 평균 2.83점, 가격대비효과 만족도는 평균 3.39점, 전 반적인 만족도는 평균 3.27 점으로 조사되었다.

여섯째, 속눈썹 연장과 일회용 속눈썹을 모두 경험해본 대상자들 의 만족도를 비교한 결과, 컬러, 길이, 불편감, 지속성, 가격대비효 과 및 전반적 만족도 점수가 속눈썹 연장에서 유의하게 높았다.

This work is part of the Kyeong-Hwa Lee's M.S. thesis at the Youngsan University, Busan, Korea.

\section{Acknowledgements}

본 연구는 2016년도 영산대학교 교내연구비 지원에 따라 수행되 었음.

\section{References}

Draelos ZD. Special considerations in eye cosmetics. Clinics in Dermatology, 19: 424-430, 2001.

Draelos ZK. Eye cosmetics. Dermatologic Clinics, 9: 1-7, 1991.

Gang EJ. The influence of the eyebrow make-up on facial image. Journal of the Korean Society of Fashion \& Beauty, 3: 31-38, 2005.

Grierson I. The eye book: eyes and eye problems explained. Liverpool University Press, Liverpool, pp31-38, 2000.

Ha So, Cho KM, Kim CS. The optical illusion effect of line applied to eyebrow make-up. Journal of Fashion Business, 9: 28-39, 2005.

Kanski JJ. Clinical ophthalmology: a systematic approach (6th edition). Butterworth-Heinemann/Elsevier, Oxford, pp94149, 2007.

Kim YS, Kang SM. A study of effects of thickness and darkness of eyeborws on images. Asian Journal of Beauty and Cosmetology, 12: 625-632, 2014.

Lim MA. A study for eyelash make up. Journal of the Korean Society of Beauty and Art, 8: 79-90, 2007.

Park JS. A mathematical analysis of eyebrow make-up design. Asian Journal of Beauty and Cosmetology, 10: 463-468, 2012.

Seol HJ. A study on a safe method of hair extension: with an emphasis on the eyelash. Journal of the Korean Society of Beauty and Art, 9: 54-65, 2008.

Shin SY. A study on changes of the eyebrows shown in the 20th century star make-up. Journal of Beauty Industry, 4: 51-66, 2010.

Volpe CR, Ramirez OM. The beautiful eye. Facial Plastic Surgery Clinics of North America, 13: 493-504, 2005.

Yang JH, Park CS, Lee JR, Lee MH, Kim GS, Ju EG, Woo MO. Make up design. Kwangmoonkag, Paju, pp93-95, 2013. 


\section{국문초록}

\section{성인여성의 속눈썹 연장 및 일회용 속눈썹 이용실태, 선호도 및 만족도 연구}

이경화, 한채정*

영산대학교 미용 · 예술대학원 미용예술학과, 부산, 한국

목적: 본 연구는 한국 성인여성의 속눈썹 연장과 일회용 속눈썹의 이용실태, 선호도 및 만족도를 조사하였다. 방법: 20 세 이상인 성인여성을 대상으로 자기기입식 설문을 실시하여 총 448부의 설문지를 회수하였고, 설문조사는 2016년 4월 30일부터 2016년 7월 30 일까지 총 10 주간 실시하였다. 결과: 총 설문 대상자 448 명 중 20 대가 $49.6 \%$ 로 가장 많았으며, 월 평균 수입이 100 만원 미만인 경우가 $24.3 \%$ 로 나타났다. 속눈썹 미용 경험이 있는 대상자들의 $83.9 \%$ 가 속눈썹 연장을 경험해보았으며, 속눈썹 미용 전문 살롱을 이용하는 경우는 $80.8 \%$ 였다. 시술 후 가장 만족하는 부분은 ‘눈이 선명해 보인다’로 $31.0 \%$ 를 차지하였으며, 속눈썹 미용 시술 이유 로는 ‘속눈썹이 길고 숱이 많게 하기 위하여’라고 응답한 경우가 $39.1 \%$ 이었다. 속눈썹 연장 선호도 및 만족도를 살펴 본 결과, 속눈 썹 연장 시 선호하는 굵기는 $0.15 \mathrm{~mm}$ (42.7\%), 검정색(75.9\%), 실크 모(29.4\%), JC컬(43.4\%), 길이는 $11 \mathrm{~mm}(42.7 \%)$, 풍성하고 자 연스러운 $80 \%$ 정도의 밀도(51.3\%)로 조사되었다. 속눈썹 연장 컬러 만족도는 평균 4.16점, 길이 만족도는 평균 4.11점, 불편감 만 족도는 평균 3.72점, 지속성 만족도는 평균 3.58점, 가격대비효과 만족도는 평균 3.83점, 전반적인 만족도는 평균 4.03점으로 조사 되었다. 일회용 속눈썹의 선호도 및 만족도로, 가장 선호하는 컬러는 검정색(77.5\%), 컬은 F컬(29.6\%), 밀도는 풍성하고 자연스러 운 80\% (42.3\%)로 나타났다. 일회용 속눈썹 컬러 만족도는 평균 3.66점, 길이 만족도는 평균 3.55점, 불편감 만족도는 평균 2.76점, 지속성 만족도는 평균 2.83 점, 가격대비효과 만족도는 평균 3.39 점, 전반적인 만족도는 평균 3.27 점으로 조사되었다. 속눈썹 연장 과 일회용 속눈썹을 모두 경험해본 대상자들에게 두 시술의 만족도를 비교한 결과, 컬러, 길이, 불편감, 지속성, 가격대비효과 및 전 반적인 만족도로 모든 만족도 항목에서 속눈썹 연장 만족도가 일회용 속눈썹에 비해 유의하게 높았다. 결론: 미용시장은 국내뿐만 아니라 전 세계적으로 각광받고 있다. 그 중 속눈썹 미용 분야는 메이크업을 지운 상태에서도 아이 메이크업을 한 듯이 또렷한 눈매 를 연출하기에 요즘 트렌드에 맞는 투명 메이크업을 자연스럽게 연출할 수 있어 여성들이 많이 선호한다. 추후에는 광범위한 지역 을 대상으로 설문과 실험이 이루어져야 할 것이며, 빠르게 변화하는 여성들의 속눈썹 미용에 대한 행태 등을 조사하여 이러한 결과 를 실제 속눈썹 미용 산업 분야에 반영하여 발전 방향을 모색해나가야 하겠다.

핵심어: 선호도, 만족도, 속눈썹 연장, 일회용 속눈썹, 성인여성

본 연구는 2016년도 영산대학교 교내연구비 지원에 따라 수행되었음.

\section{참고문헌}

강은주. 눈썹화장이 얼굴이미지에 미치는 영향. 한국패션뷰티학회지, 3: 31-38, 2005.

김영삼, 강상모. 눈썹의 짙기 정도가 이미지에 미치는 영향. 아시안뷰티화장품학술지, 12: 625-632, 2014.

박정신. 눈썹메이크업 디자인의 수리적 분석 연구. 아시안뷰티화장품학술지, 10: 463-468, 2012.

설현진. 안전한 모발연장술에 관한 연구: 속눈썹 중심으로. 한국인체미용예술학회지, 9: 54-65, 2008.

신석영. 20세기 스타메이크업에 나타난 눈썹화장 변화에 관한 연구. 뷰티산업연구, 4: 51-66, 2010.

양진희, 박춘심, 이종란, 이미희, 김광숙, 주은경, 우미옥. 메이크업 디자인. 광문각, 파주, pp93-95, 2013.

임미애. 속눈썹 화장에 관한 연구. 한국인체미용예술학회지, 8: 79-90, 2007.

하선옥, 조고미, 김춘심. 눈썹 메이크업 표현(表現)에 응용(應用)되는 선(線)의 착시(錯視) 효과(效果). 패션 비즈니스, 9: 28-

39, 2005. 


\section{中文摘要}

\section{成年女性睫毛延长和假睷毛的使用状态，偏好以及满意度研究}

李京和, 韓采廷

灵山大学美容艺术大学院美容艺术科, 釜山, 韩国

目的: 调查韩国女性的睫毛延长和假㫸毛的使用状态，偏好以及满意度。方法: 以20岁以上的成年女性为对象进行自我 管理问卷调查，共收集了448份资料，调查期间从2016年4月30日至2016年7月30日，为期10周。结果：在448名调查对象 中, 其中 20 岁以上以 $49.6 \%$ 占最多, 月平均收入为 100 万韩元以下占 $24.3 \%$ 。具有睫毛美容经验的对象中, 其中 $83.9 \%$ 做 过睫毛延长; $80.8 \%$ 利用专业睫毛美容院; 睫毛美容之后, 最满意的部分为“眼睛看起来清晰”, 占 $31.0 \%$; 进行睫毛美容 的理由中, 回答“为了让睫毛看起来更长, 丰盛” 占 $39.1 \%$ 。睫毛延长偏好以及满意度调查结果显示：睫毛延长时, 优选条 件为 $0.15 \mathrm{~mm}$ 厚度 $(42.7 \%)$ 、黑色 (75.9\%) 、丝质毛 (29.4\%)、JC卷（43.4\%）、11 mm长度 $(42.7 \%)$ 以及丰盛 和自然的 $80 \%$ 密度 (51.3\%) ; 睫毛延长满意度为平均 4.16 分, 长度满意度为平均4.11分, 舒适度满意度为平均 3.72 分, 持续性满意度为平均 3.58 分, 性价比满意度为平均 3.83 分, 整体满意度为平均 4.03 分。假䀨毛偏好以及满意度调查结果显 示：最喜欢的颜色为黑色（77.5\%），卷曲为F卷（29.6\%），密度为丰盛和自然的 $80 \% （ 42.3 \% ）$; 假睫毛的颜色满意 度为平均 3.66 分, 长度满意度为 3.55 分, 舒适度满意度为平均 2.76 分, 持续性满意度为平均 2.83 分, 性价比满意度为平均 3.39分, 整体满意度为 3.27 分。使用过睫毛延长和假睫毛两种对象中, 满意度比较结果显示: 在颜色、长度、舒适度、 持续性、性价比以及整体满意度等项目中，睫毛延长比假睫毛满意度明显较高。结论：美容市场在国内外备受关注。其 中, 眏毛美容在擦除彩妆的情况下, 产生一种清澈的眼貽, 这种自然透明的妆容适合潮流，女性更喜欢。今后需进行广 泛的调查和实验, 对迅速变化的女性睫毛美容状态进行调查, 并将结果反映在睫毛美容行业领域, 探索发展方向。

关键词: 偏好, 满意度, 睫毛延长, 假睫毛, 成年女性 